\title{
INNOVATION IN TEACHING: THE POLIMAPPERS COLLABORATIVE AND HUMANITARIAN MAPPING COURSE AT POLITECNICO DI MILANO
}

\author{
Federica Gaspari ${ }^{1, *}$,Lorenzo Stucchi ${ }^{1}$, Gorica Bratic $^{1}$, Dina Jovanovic ${ }^{1}$, \\ Chiara Ponti ${ }^{1}$, Ludovico Giorgio Aldo Biagi ${ }^{1}$, Maria Antonia Brovelli ${ }^{1}$

\begin{abstract}
${ }^{1}$ Politecnico di Milano, Department of Civil and Environmental Engineering, Piazza Leonardo da Vinci, 20133 Milano, Italy (federica.gaspari, lorenzo.stucchi, gorica.bratic, dina.jovanovic, ludovico.biagi, maria.brovelli)@polimi.it, chiara.ponti@mail.polimi.it
\end{abstract}

\section{Commission IV, WG IV/4}

KEY WORDS: Open Geospatial Data, Open Geospatial Software, Open GeoEducation, OpenStreetMap, Participatory Mapping

\begin{abstract}
:
Collaborative projects imply a wide variety of skills, ranging from technical abilities to teamwork and problem-solving attitudes. Innovative teaching programmes focused on the use and promotion of open-source geospatial tools represent a key element in developing such transversal abilities. OpenStreetMap (OSM) brings into play open and collaborative dynamics that build a critical ecosystem where single contributions are part of collective intelligence. This initiative led to the foundation of structured contributors groups such as PoliMappers, the first European YouthMappers chapter based in Politecnico di Milano (Italy). Pursuing the objective to build a responsible student-led community of Free and Open Source Software users, in 2021 PoliMappers organised the course entitled "Collaborative and Humanitarian Mapping". The programme is structured into 7 meetings and aims to introduce university students to the OSM environment with a focus on the potential of open data and related geospatial tools, especially in the humanitarian field. It has seen the participation of the World Food Programme, Open Knowledge Foundation, TECHO Colombia, IMM Design Lab, Map for Future, UN Mappers, Spazio Vita Niguarda Onlus, Ledha Milano, AUS Niguarda Onlus and Humanitarian OpenStreetMap Team. Enrolled attendants' contributions have been assessed with tools for quality review and statistics. Also, Q\&As and suggestions to the attendants have been collected to detect common issues. The paper presents the course, from the design to the assessment of the students' activities, and the lessons learned in this experience in such a way to provide some guidance to those who want to organize similar initiatives.
\end{abstract}

\section{INTRODUCTION}

Societal needs and available technologies evolve in time: to be aligned, also educational methodologies (Kolb, 1984) should innovate: active learning is one specific innovative methodology that is applied and discussed in this paper. Active learning "can be defined as anything that involves students in doing things and thinking about what they are doing" (Auster and Wylie, 2006). Active learning in technical disciplines implies that students freely access specific software and data: this clearly holds also for learning relevant to geospatial data and software: Coetzee et al. (2020) state that "Openness typically refers to transparency, to free and unrestricted access to information, and inclusive consensus-based decision-making".

OpenStreetMap (OSM) is an open worldwide geospatial database, that has been created and is updated by volunteers (OSM, 2021). There are three possible ways to contribute to OSM:

1. bulk import: import of external openly-licensed datasets,

2. field mapping: a field survey of the area to be mapped;

3. remote mapping: digitizing map objects by satellite or aerial imagery.

Depending on the contribution objectives, each option has advantages and disadvantages: for example the location of villages in remote areas can be efficiently mapped by satellite

\footnotetext{
* Corresponding author
}

images while the mapping of accessibility of urban footways (Biagi et al., 2020) strictly requires field survey.

In the last decade, OSM has been widely used in humanitarian projects, mainly under the guidance of the Humanitarian OSM Team (HOT (2021)) and the Missing Maps project (Missing Maps (2021)). The openness makes OSM perfect for educational purposes (Yordanov et al., 2020), at least at two different levels: firstly, the data model can be studied in any technical detail; then, the free data can be used by students without the need of paying any fee or license; this clearly holds also for free and open software that is available to upload and navigate OSM, like JOSM (JOSM Development Team (2021)) and QGIS (QGIS Development Community (2021)).

A mapathon is a specific action to contribute to OSM: it can be defined as a collaborative effort aimed at collecting specific map data in places where OSM data is scarce or non-existent. Mapathons can be performed by groups of volunteers who meet in a place to collectively work by remote mapping; alternatively, volunteers can work in virtual sessions of remote connections: this last practice has been the one adopted during the last year of pandemic. Effectiveness, accuracy, and reliability of mapathons outcomes have been widely investigated and assessed over the last years: see, for example, Coetzee et al. (2018), Green et al. (2019). Mapathons volunteers can be university students, that is the focus of this paper, but also children in primary schools and retired citizens: for example, Ebrahim et al. (2016) describe an experiment of humanitarian mapathon that involved 10-year old 
children. Mapathons constitute a clear example of active learning. Volunteers are shortly introduced to the purposes, software, and data; then, they actively learn by mapping.

In the academic year 2018/2019, Politecnico di Milano started to promote innovative teachings by several actions: Passion in Action ((Politecnico di Milano, 2021)) is a catalogue of open participation teaching activities that are offered to support the development of transversal, soft and social skills and to encourage students in enriching their personal, cultural and professional experience. Students may choose from a range of subjects and apply them to any action.

\section{YOUTHMAPPERS AND POLIMAPPERS}

YouthMappers is an international network of universitystudent-led chapters (YouthMappers (2021)). The vision of the network is to cultivate a generation of young people that will develop leadership skills and create resilient communities around the world and to empower youth to define and change their world by mapping it. YouthMappers aims to be a reference point in the academic sector to find resources for participating in open mapping initiatives for humanitarian and development purposes. Students who are members of the network can apply for research grants and internship programmes, and have access to teaching materials.

The network was founded in 2015 by Texas Tech University (TTU), The George Washington University (GWU), and West Virginia University (WVU), followed by more than 260 chapters (Figure 1). It is supported by the United States Agency for International Development (USAID) through a grant from the USAID GeoCenter.

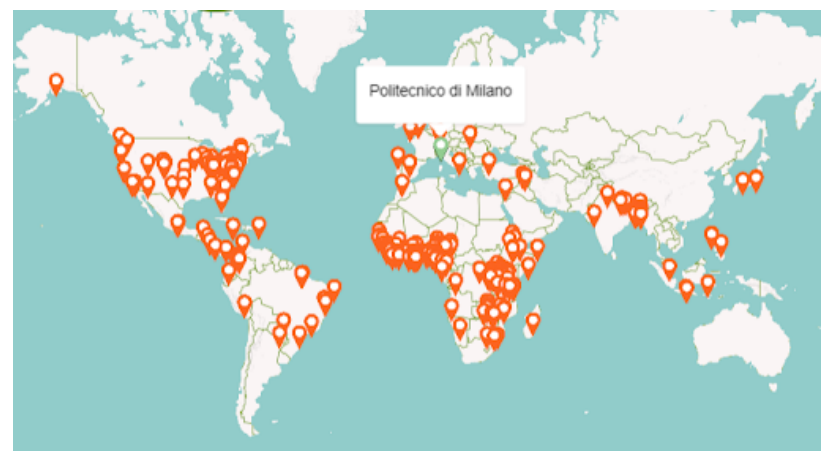

Figure 1. YouthMappers chapters locations. Source:https://www.youthmappers.org/.

PoliMappers is a group of students of Politecnico di Milano whose main goal is to promote mapping, leverage the use of free and open source technologies in order to train and motivate the next generation of volunteer mappers (PoliMappers, 2021). Established in 2016, PoliMappers is the 1st Chapter in Europe of YouthMappers.

The main activities of the group include: indoor and outdoor mapping with Field Papers; training and seminars to the members on topics related to new services and tools for mapping; engaging with the local communities by teaching to everyone from kids to adults - and promoting mapping activities such as "mini-mapathons"; participating in humanitarian "mapathons" (mapping campaigns) coordinated by the HOT as well as Missing Maps projects aimed to bring OSM coverage to those areas where there is no cartography; collaborating with other chapters of the YouthMappers network and with NGOs and organisations active in the field by organising joint events and campaigns (Figure 2).
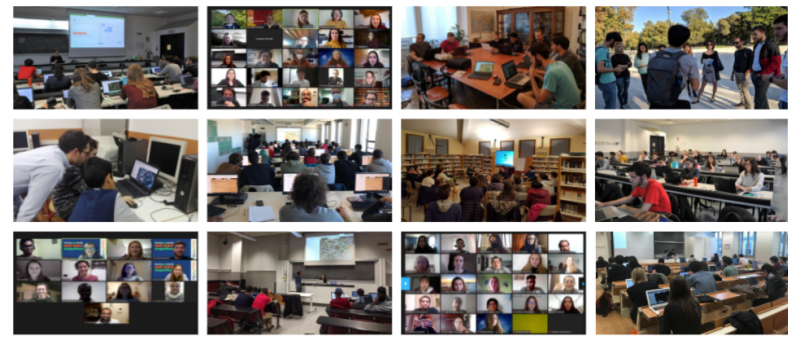

Figure 2. PoliMappers activities. Source: https://polimappers.github.io/

\section{THE COLLABORATIVE AND HUMANITARIAN MAPPING COURSE}

The Passion in Action course "Collaborative and Humanitarian Mapping" was designed keeping in mind the principles and the ideas at the basis of the PoliMappers group: promotion of the use of free open source geospatial tools and involvement of students at different levels of their university path. The total amount of the 20 hours was then structured in 7 meetings on the Zoom broadcasting platform during which attendants had the opportunity to follow a journey into the OSM project with gradual steps, gaining hands-on experience while participating in webinar, workshops and mapping sessions. Initially, the course was scheduled to be held in presence but, due to the COVID-19 pandemic restrictions in Italy, the entire programme was re-organised as distance learning, making the contents accessible also to people not enrolled in any Politecnico di Milano course. For this reason, particular attention was given to the choice of the broadcasting platform, considering its availability also with low bandwidth and possibility of breakout rooms to better manage specific issues during the meetings.

The programme ranged from humanitarian mapping and climate change awareness to open collaboration (Table 1). In this way, the lectures offered a wide variety of topics to be discussed also in question and answer (Q\&A) sessions with the attendants. Moreover, the choice of presenting examples of different OSM-related projects led to the involvement of other organisations at the local (IMM Design Lab, Map for Future, Spazio Vita Niguarda Onlus, Ledha Milano, AUS Niguarda Onlus) as well as the global scale (World Food Programme, YouthMappers, Open Knowledge Foundation, TECHO Colombia, UN Mappers, and Humanitarian OpenStreetMap Team). Hence, the activities of the course and their difficulty level allowed students to gain confidence with various map features (buildings, land uses, waterways, highways as well as points of interest) using technologies like iDeditor, JOSM and Mapillary (Mapillary Development Team, 2021). Contributing through Teach OSM and HOTOSM Tasking Manager (Humanitarian OpenStreetMap Team, 2021), attendants managed to become more familiar with community-led and sustained coordinating platforms, making it possible to track their activity too. Indeed, PoliMappers officers in the days following the lectures monitored project-related hashtags (ResultMaps (Pascal Neis, 2021), CartONG Mapathon Dashboard (CartONG, 2021)) and validated the contributions with OSMCha (Wille Marcel, 2021) 


\begin{tabular}{|l|l|}
\hline Meeting Title & Day \\
\hline $\begin{array}{l}\text { OpenStreetMap introduction and } \\
\text { mapping session with iD editor }\end{array}$ & March 5th, 2021 \\
\hline $\begin{array}{l}\text { Mapping deforestation in the Amazon } \\
\text { rainforest with JOSM }\end{array}$ & March 12th, 2021 \\
\hline $\begin{array}{l}\text { Mapping informal settlements in } \\
\text { Bogotá }\end{array}$ & March 26th, 2021 \\
\hline $\begin{array}{l}\text { Humanitarian Mapping with Map for } \\
\text { Future }\end{array}$ & April 16th, 2021 \\
\hline $\begin{array}{l}\text { Humanitarian Mapping with UN } \\
\text { Mappers }\end{array}$ & April 30th, 2021 \\
\hline $\begin{array}{l}\text { ViaLibera?! Project: mapping access- } \\
\text { ibility with Mapillary and JOSM }\end{array}$ & May 7th, 2021 \\
\hline $\begin{array}{l}\text { Humanitarian OpenStreetMap Team: } \\
\text { Final discussion }\end{array}$ & May 21st, 2021 \\
\hline
\end{tabular}

Table 1. Summary of the course lessons and calendar

quality assurance tool, giving feedback and suggestions to the students with comments on their changesets.

Special attention was also dedicated to the promotion of the events, using the most popular social media platforms (Facebook, Instagram, Twitter, LinkedIn). These network communication enabled PoliMappers to involve a diverse audience also outside Politecnico di Milano that, through a dedicated form, had the opportunity to join the events on Zoom or follow their live-streaming on Twitch, where all the meetings were transmitted using Open Broadcaster Software (OBS Studio Contributors, 2021).

\subsection{OpenStreetMap Introduction and mapping session with iD editor (March 5th)}

The lecture series took off on March 5th, with an event hosted as part of Open Data Day week, the annual celebration of open data around the world. During the event, participants were introduced to the world of collaborative mapping through an overview of the OSM project and a mapping activity suitable for beginners. OSM was presented not only as a database, but also as a community, which is active in every aspect of the project, from simple mapping to adoption of conventions and participation in working groups. Basic concepts in terms of geometric representation and descriptive tagging were presented, as well as examples of outdoor, remote and bulk import mapping. iDeditor (iD Editor Development Team, 2021), JOSM and mobile editors like Vespucci (Vespucci Development Community, 2021) and Go Map!! (Bryce Cogswell, 2021) were mentioned, to show the students in how many different ways one can contribute.

To give the students a first concrete example of how the OSM database has become of fundamental importance for humanitarian services, Dimitris Karakostis, Technical Manager and Senior Geospatial Officer at World Food Programme (WFP), explained to the participants how WFP uses OSM to update its mapping resources and thus provide optimal support to people working on the field. Karakostis' presentation revealed the close interconnection of open databases and tools with the nature of missions and WFP as a whole.

The students seemed very attracted by the applications of OSM data in the humanitarian field, in particular the automatic topographic map production system developed by the WFP (which uses OSM as one of the sources), and the possibility of using artificial intelligence to speed up the mapping process. Finally, a short tutorial to learn how to map buildings with iDeditor was given. Participants then collaborated on mapping project \#1148 (TeachOSM, 2021c) "Mapping Tartus", created to enrich the geographical information of that area of Syria, where WFP is operating.

The practical part of the event produced good results in terms of quantity (more than 50 OSM users mapped over 5000 buildings) and quality, in fact the contributions were validated by the PoliMappers team and in general a good level of mapping was found. The audience for the first meeting of the course was also the largest: more than 90 people attended, about half of whom were officially registered as students at the Politecnico di Milano, with the remainder coming from outside (details about mapped features in Table 2).

\begin{tabular}{|l|l|}
\hline Feature & Amount \\
\hline Buildings & 4166 \\
\hline Roads & $1151.1 \mathrm{~km}$ \\
\hline Land use area & $7.75 \mathrm{~km}^{2}$ \\
\hline
\end{tabular}

Table 2. Mapping results of the first course meeting. Source: resultmaps.neis-one.org/, https://mapathon.cartong.org/

\subsection{Mapping deforestation in the Amazon rainforest with JOSM (March 12th)}

The primary goal of the second lesson was to introduce JOSM - an advanced desktop OSM editor - to students. During the lesson, it was explained how to set up the software and how to use it to contribute to the OSM database. Overall, it was explained how to connect software to an OSM user account, install plugins, select an area in which to add features, select a base map, add additional base maps, assign tags to features, use a predefined set of tags, and finally how to add features to OSM.

This lesson was designed to support a 2020 Youth Mappers research fellowship project named "Cross-continental YouthMapping for deforestation in Amazonian region" that aims at the creation of a deforestation risk model. The data collected by the students will be used for training and validation datasets for the development of the risk model i.e. land cover map. The area of interest is an area in the northeast of Mato Grosso state in Brazil, which was identified as one of the deforestation hotspots in 2020 by Monitoring of the Andean Amazon Project (MAAP). The area of interest also includes the indigenous land of Xingu. To keep mapping in the target area, seven TeachOSM projects were created (TeachOSM, 2021a). Features requested for deforestation mapping were different types of roads, waterways, buildings, and land use. These features are useful for identifying which features replaced primary forest as a proxy to the activities that drive deforestation in the area of interest. Each TeachOSM project was accompanied by extensive instructions on recognizing different features relevant for deforestation mapping and assigning them with a proper tag. Moreover, the teaching materials used during the lesson had examples of how each feature looks like in a satellite image and how to trace it and associate it with the proper tag in JOSM. Finally, what was included in the teaching materials was also shown practically to students.

For this lesson, students of the course had the assignment to complete one task in one of the TeachOSM projects. The result of 23 contributions is summarised in the Table 3. 


\begin{tabular}{|l|l|}
\hline Feature & Amount \\
\hline Roads & $2092.3 \mathrm{~km}$ \\
\hline Buildings & 560 \\
\hline Land use area & $693.22 \mathrm{~km}^{2}$ \\
\hline Rivers & $495.3 \mathrm{~km}$ \\
\hline
\end{tabular}

Table 3. Mapping results of the second course meeting. Source: resultmaps.neis-one.org/, https://mapathon.cartong.org/

\subsection{Mapping informal settlements with Mapillary and OSM (March 26th)}

The project for the third meeting of the course introduced the students to the world of crowdsourced street-level imagery. Indeed, the collaboration with IMM Designlab - an international and multidisciplinary design laboratory for urban sustainability based at Politecnico di Milano - led to the development of an international community project in three steps involving the integration of Mapillary data in the OSM environment as part of a master thesis focused on slums upgrading. The project proposes an integrated design approach for the environmental performance and social inclusion in the border between Bogotá and Soacha (Colombia). First, in the weeks preceding the course meeting, PoliMappers officers designed together with the master thesis students the different phases of the collaboration. The preparation consisted in contacting local volunteers from TECHO Colombia active in the case study area and providing them a 2 hours training on the use on field of Mapillary application. Then, the 5171 images collected and uploaded on Mapillary by 4 TECHO collaborators along 32 street kilometers represented the starting point for the mapathon held during the course.

Indeed, on the occasion of the third meeting, students learned how to use collectively captured photo sequences combined with traditional OSM-editing performed in ID editor. In this way, they had the opportunity to improve the level of details of maps in informal urban areas usually not considered by official cartographic products while getting familiar with point map features. After a 2-hours tutorial about shops and amenities tagging and Mapillary sequences visualisation in ID editor, 39 contributors managed to contribute a total of 830 map changes in the dedicated project published on TeachOSM (Project 1270 (TeachOSM, 2021b)). The activities fostered the discussion on the quality and quantity of map data and on the importance of local knowledge, especially for features that are particularly connected to the mapping context and area. The contributions are reported in Table 4.

\begin{tabular}{|l|l|}
\hline Feature & Amount \\
\hline Shops & 508 \\
\hline Amenities & 177 \\
\hline Healthcare places & 17 \\
\hline
\end{tabular}

Table 4. Mapping results of the third course meeting. Source: resultmaps.neis-one.org/, https://mapathon.cartong.org/

\subsection{Humanitarian Mapping with Map for Future (April 16th)}

The guest speakers from a non-profit organization from Rome, Map for Future, gave their contribution joining the fourth meeting. They are dedicated to the usage of tools of Digital Cartography to support the most sensitive and disadvantaged areas in the world. The organisation was created with the help of Una
Quantum Inc., which is a non-profit cultural association based in Rome that funds and promotes development and propagation of software and hardware for management and enhancement of cultural heritage. Brief introduction and rods of support offered President of Una Quantum Inc., Roberto Montagnetti.

The meeting started with the presentation of co-founders of Map for Future, Ph.D. Giuseppe Maria Battisti and eng. Valerio De Luca, who gave the students valuable insights of the real implementation of their work, as well as potentialities and constraints of the projects. They tangled important topic of collaboration with the local community. The representative of the local community in the online meeting was Abdillahi Hassan from Somaliland, who is a project manager of GIS \& Cadastral Survey.

The students had the opportunity to hear about the Somaliland project and creation of the geoportal, with the help of remote and local mappers. After the presentation, followed by the tutorial, students needed to map the task on HOT Tasking Manager (10688 (HOTOSM TM, 2021b)) opened by Map for Future member and validator Ph.D. Maria Luisa Pisanelli. The task was mapping private areas in the city of Wajaale on the border of Somaliland and Ethiopia, more precisely mapping fences of the private courtyards. Special attention was paid to the connection between two neighbourhood fences which share the same nodes and to the openings and gates, which represent the interruption in the mapping line feature. This exercise for students will help in the future Map for Future to calculate private surfaces in the city. Students had the opportunity to choose the editor they prefered, iD Editor or JOSM, which were introduced to them in the previous meetings, using the line feature with the key: barrier and value: fence. The result of the mapathon recorded the active contribution of 40 people and a total of 14311 map changes (Table 5).

\begin{tabular}{|l|l|}
\hline Feature & Amount \\
\hline Nodes & 12426 \\
\hline Ways & 1351 \\
\hline
\end{tabular}

Table 5. Mapping results of the fourth course meeting. Source: resultmaps.neis-one.org/, https://mapathon.cartong.org/

\subsection{Humanitarian Mapping with UN Mappers (April 30th)}

With the goal of broadening the discussion on the role of OSM data in humanitarian context, the fifth meeting of the Passion in Action course saw the participation of members from the Unite Maps Initiative, a programme run by the United Nations Global Service Centre. The coordinators of the Crowdsourcing team, Michael Montani and Rachele Amerini, illustrated the mission of the group, highlighting how they are currently adopting strategies based on OSM in order to support the UN peacekeeping missions on field. In particular, the attendants of the meeting had the opportunity to understand the role of their contribution on OSM for the creation of up-to-date topographic products and for enabling the adoption of navigation tools useful to reach communities in remote places.

After the introductory part, the students followed a mapping training that showed how to map points of interest, waterways, highways and land uses. The peculiarities of the Sudan mapping areas assigned on the HOT Tasking Manager (Project 10800 (HOTOSM TM, 2021a)) engaged the participant in a discussion on the importance of knowing the context of the project. 
Indeed, the explanations on how the road system is structured in Africa raised again awareness on the crucial role played by local knowledge for mapping in the most accurate way possible the features that can be detected on satellite images. During the mapathon and in the following two weeks, 13 contributors scored a total of 44051 map changes (Table 6).

\begin{tabular}{|l|l|}
\hline Features & Amount \\
\hline Land use area & $8.46 \mathrm{~km}^{2}$ \\
\hline Highways & $513.32 \mathrm{~km}$ \\
\hline Rivers & $113.58 \mathrm{~km}$ \\
\hline
\end{tabular}

Table 6. Mapping results of the fifth course meeting. Source: resultmaps.neis-one.org/, https://mapathon.cartong.org/

\subsection{ViaLibera?! Project: mapping accessibility with Mapillary and JOSM (May 7th)}

The sixth lesson presented to the participants the project "ViaLibera?!". The project aims to map the physical barriers present in the Municipality 9 of the city of Milano (Italy). The partners of the project are associations of people with disabilities (Spazio Vita Niguarda Onlus, LEDHA Milano and AUS Niguarda Onlus) and the technical partner Politecnico di Milano. Also, the project is supported by Municipality 9 and the city department for mobility AMAT.

The mapping activity was the most detailed presented in the course; the project collects information about sidewalks, crossing and kerbs into OSM. Multiple methodologies are suitable for the collection of this information (Biagi et al., 2020); however, due to the pandemic situation and the modality of the course, the students were asked to map only from remote. The elements suitable for this type of mapping are only sidewalks and crossings using JOSM. Due to the possible complexity of the mapping, the project created a preset available in JOSM for simplifying the complex tagging schema requested for this type of mapping.

The participants were asked to map the neighbourhood of Dergano collaborating into mapping project 1299 in the Teach OSM Tasking Manager (TeachOSM, 2021d). The activity recorded the participation of 17 contributors with more than 90 changesets that mapped more than $20 \mathrm{~km}$ of sidewalks and crossings.

\subsection{Humanitarian OpenStreetMap Team: Final discus- sion (May 21st)}

After a series of meetings full of concepts and activities, it was decided to structure the last appointment of the course in a slightly different way. The aim was to introduce participants to some of the faces working in the vast world of humanitarian mapping. For this reason, Geoffrey Kateregga, Community Programs Manager, and Miriam Gonzalez, HOT Board President, were invited as speakers.

The first part of the meeting was dedicated to the mapping results obtained during the lessons by the students and to an overview of the different skills they learned throughout the course. A feedback questionnaire was given to the participants and later sent to all the people registered to the course.

Geoffrey Kateregga gave his perspective on the world of humanitarian mapping, both as a member of the community working group and as a volunteer mapper. His presentation about the different working groups within HOT well expressed the concept of 'community of communities', a plurality of visions that can make a difference when it comes to creating an inclusive and diverse map.

Miriam Gonzalez provided some examples humanitarian missions that have used or are aimed at collecting open geographical data through OSM where she has been personally involved in. Her passionate and pragmatic speech encouraged students and participants to come up with ideas for projects involving their local communities.

\section{EVALUATION OF THE ACTIVITIES AND FEEDBACK FROM THE STUDENTS}

A total of twenty-five students answered the feedback questionnaire which was sent after the last meeting. Most of them, $44 \%$ of students heard about the PoliMappers Collaborative and $\mathrm{Hu}-$ manitarian Mapping course through their professors, following the other $24 \%$ which were informed about the course through the Politecnico di Milano website (Figure 3 and 4).

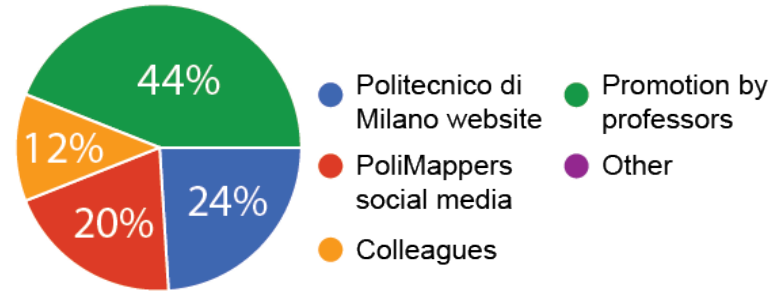

Figure 3. How students heard about the course.

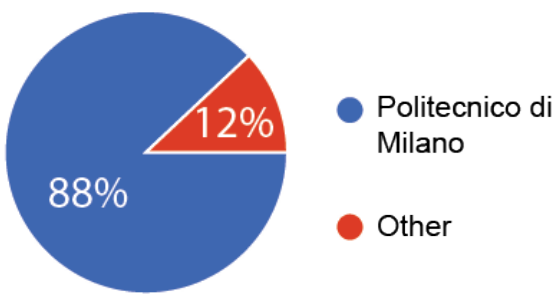

Figure 4. Percentage of students enrolled at Politecnico di Milano.

All students participating in filling the feedback questionnaire were attending the first two meetings and by time that percentage decreased. This gives the conclusion that the most important topics and basic knowledge skills should be covered in the first meetings, and more specific instructions should be delivered throughout the later meetings (Figure 5).

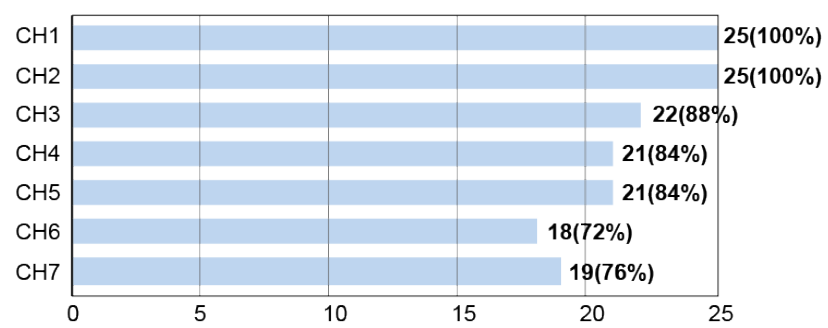

Figure 5. Participation of the students on seven meetings delivered through Passion in Action course.

None of the participants stated that they are experienced contributors in the mapping of OpenStreetMap. While 28\% had 
never heard about OpenStreetMap before, 36\% of students stated that they are beginner mappers and that they have been contributing at least once. In conclusion, the span of knowledge of students participating in the course is from the very beginner without previous knowledge until the beginner mapper (Figure 6).

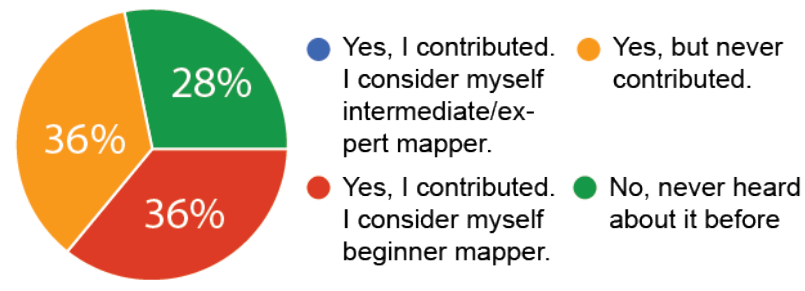

Figure 6. Percentage of students' knowledge about OpenStreetMap project.

Starting from the very beginning, this course gave an introduction to the basic content and skills needed to start contributing to the mapping activities. Most of the students said that the course does not need prior knowledge (92\%) (Figure 7). Since the majority of the students stated that they are beginners in mapping activities, the course showed success in delivering the right content to the goal group.

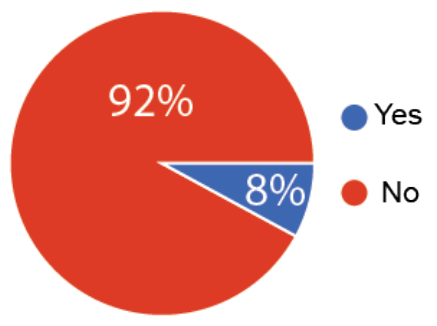

Figure 7. Percentage of students said that there is (not) a need for prior knowledge to attend the course.

The review and validation of the activities of the students made possible to follow the evolution of their learning journey along the course. At first, common mistakes were related to the lack of experience of beginner contributors: in particular, validators detected buildings not orthogonalised, overlapping features, element duplicates and misspelled tags. These problems could also be related to the fact that the majority of the contributions were made through iD Editor, which is strongly suggested for beginners but not equipped with user-friendly error detection tools that could help to automatically identify geometric and semantic inconsistencies within feature edits. The introduction of the use of the JOSM editor enabled students to improve their mapping accuracy. Indeed, it makes available advance tools for understanding quality assurance like "Validation results" and "Conflict" tabs. As lectures progressed, errors were due more to image misinterpretation, use of words in different languages for tag values and unusual tag combinations not recognisable by JOSM.

In their final evaluation form, attendants had also the opportunity to rate each meeting in terms of topics difficulty, seminar and mapping tutorial clarity with a value from 0 (very low) to 5 (very high). Eventually, all the 7 meetings, concerning projects located in 6 different countries (Figure 8), received ratings above the average of 3 for both difficulty and clarity. However, comments from participants addressed the difficulty in mapping for projects where local knowledge represented a key element. In particular, the third meeting focused on the mapping of informal urban settlements was reviewed as highly challenging and complex due to the difficulty in understanding a geographical context very different to the one to which the attendants are used to, and to the troubles linked to the post-processing of images on the Mapillary platform (problems in detecting clearly the viewing angles and/or the photo sequence direction).

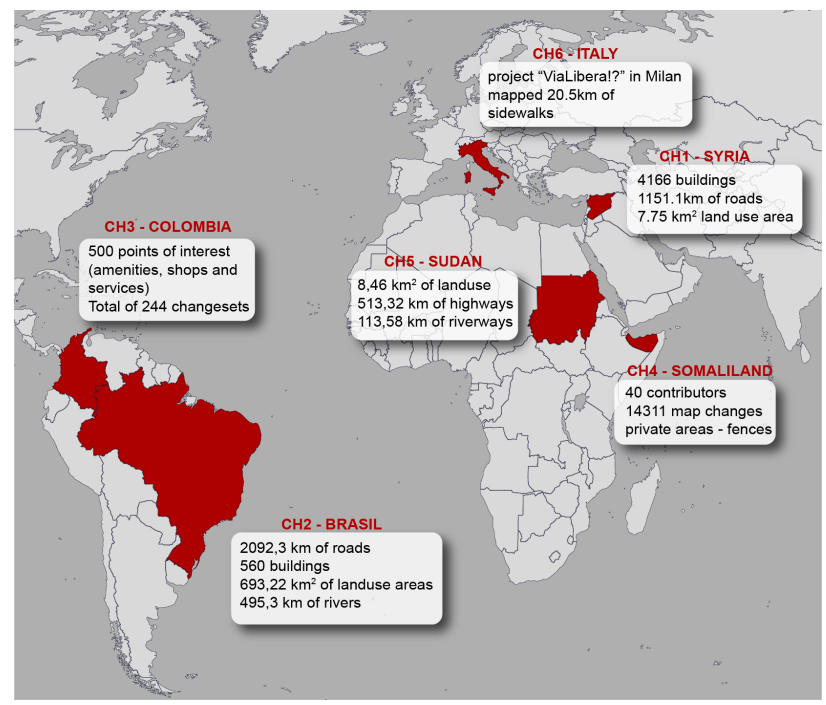

Figure 8. Location and details of the projects proposed to the students.

\section{CONCLUSIONS}

The experience of the Collaborative and Humanitarian Mapping course led to the involvement of students with different levels of experience related to OpenStreetMap and/or mapping. The design of the course allowed to gradually show a wide variety of collaborative and open-source tools, making possible to foster a learning journey that had progressively enabled attendants to be more familiar with the technical environment and more responsible about the quality of their contribution. Indeed, the progress in time in terms of quantity and quality of the contribution confirmed a strong interest in the proposed topics, as also mentioned in comments on the final evaluation form.

Furthermore, the wide variety of the proposed activities presented a broad spectrum of possible applications of tools and contexts, ranging from humanitarian crisis responses to urban studies. The projects explored during the course through practical and unconventional student-led sessions engaged the students in cultivating new skills or exploiting interests that probably could not have been discovered through traditional study programmes at university. Finally, the response of the students at the end of the lessons suggests that this kind of innovative teaching course could represent an opportunity to be considered in order to motivate and help learners to approach relevant topics in alternative ways.

\section{REFERENCES}

Auster, E. R., Wylie, K. K., 2006. Creating active learning in the classroom: A systematic approach. Journal of management education, 30(2), 333-353. 
Biagi, L., Brovelli, M., Stucchi, L., 2020. Mapping the Accessibility in Openstreetmap: a Comparison of Different Techniques. ISPRS-International Archives of the Photogrammetry, Remote Sensing and Spatial Information Sciences, 43, 229236.

Bryce Cogswell, 2021. Go Map!! https://github.com/bryceco/ GoMap. [Online; accessed 10-June-2021].

CartONG, 2021. CartONG Mapathon Dashboard. https:// mapathon.cartong.org/. [Online; accessed 10-June-2021].

Coetzee, S., Ivánová, I., Mitasova, H., Brovelli, M. A., 2020. Open geospatial software and data: A review of the current state and a perspective into the future. ISPRS International Journal of Geo-Information, 9(2), 90.

Coetzee, S., Minghini, M., Solis, P., Rautenbach, V., Green, C., 2018. Towards understanding the impact of Mapathons-Reflecting on youthmappers experiences. International Archives of the Photogrammetry, Remote Sensing and Spatial Information Sciences-ISPRS Archives, 42(4W8), 3542.

Ebrahim, M., Minghini, M., Molinari, M. E., Torrebruno, A. et al., 2016. Minimapathon-mapping the world at 10 years old. 8th International Conference on Education and New Learning Technologies, IATED, International Association of Technology, Education and Development, 4200-4208.

Green, C., Rautenbach, V., Coetzee, S., 2019. Evaluating Student Motivation and Productivity during Mapathons. ISPRSInternational Archives of the Photogrammetry, Remote Sensing and Spatial Information Sciences, 4214, 85-91.

HOT, 2021. Humanitarian OpenStreetMap Team. https://www. hotosm.org/. [Online; accessed 14-June-2021].

HOTOSM TM, 2021a. Nazioni Unite per Abyei - BADRĪYAH: strade, corsi d'acqua e villaggi - Project 10800. https://tasks. hotosm.org/projects/10800. [Online; accessed 14-June-2021].

HOTOSM TM, 2021b. Somaliland Wajaale Fences 2013 - Project 10688. https://tasks.hotosm.org/projects/10688. [Online; accessed 14-June-2021].

Humanitarian OpenStreetMap Team, 2021. HOT Tasking Manager. https://tasks.hotosm.org/. [Online; accessed 10-June2021].

iD Editor Development Team, 2021. iD Editor. http://ideditor. com/. [Online; accessed 10-June-2021].

JOSM Development Team, 2021. Java OpenStreetMap (JOSM) Software. https://josm.openstreetmap.de/. [Online; accessed 10-June-2021].

Kolb, D., 1984. Experiential Learning: Experience as the Source of Learning and Development, 347 Prentice-Hall. Englewood Cliffs, NJ.

Mapillary Development Team, 2021. Mapillary. https://www. mapillary.com/. [Online; accessed 10-June-2021].

Missing Maps, 2021. Missing Maps Project. https://www. missingmaps.org/. [Online; accessed 14-June-2021].

OBS Studio Contributors, 2021. Open Broadcaster Software (OBS) Project. https://obsproject.com/. [Online; accessed 14June-2021].
OSM, 2021. OpenStreetMap. https://www.openstreetmap.org. [Online; accessed 14-June-2021].

Pascal Neis, 2021. ResultMaps. https://resultmaps.neis-one. org/. [Online; accessed 10-June-2021].

PoliMappers, 2021. PoliMappers. https://polimappers.github. io/. [Online; accessed 14-June-2021].

Politecnico di Milano, 2021. Politecnico di Milano - Passion in Action Catalogue. https://www.polimi.it/en/programmes/ innovative-teaching/. [Online; accessed 14-June-2021].

QGIS Development Community, 2021. QGIS Project. https:// www.qgis.org/. [Online; accessed 14-June-2021].

TeachOSM, 2021a. Amazon Deforestation - Projects 1054-1058; 1060-1061. https://tasks.teachosm.org/explore? campaign=Amazon \%20Deforestation\%20-\%20PoliMappers\% 20\%26\%20YouthMappers\&text=Amazon\%20deforestation.

[Online; accessed 14-June-2021].

TeachOSM, 2021b. Mapping informal settlements in Bogotà using Mapillary sequences - Project 1270. https://tasks. teachosm.org/projects/1270. [Online; accessed 14-June-2021].

TeachOSM, 2021c. Mapping Tartus - Project 1148. https:// tasks.teachosm.org/projects/1148. [Online; accessed 14-June2021].

TeachOSM, 2021d. Via Libera - Project 1299. https://tasks. teachosm.org/projects/1299. [Online; accessed 14-June-2021].

Vespucci Development Community, 2021. Vespucci. https:// vespucci.io/. [Online; accessed 10-June-2021].

Wille Marcel, 2021. OSMCha. https://osmcha.org/. [Online; accessed 10-June-2021].

Yordanov, V., Brovelli, M., Carrion, D., Barazzetti, L., Francisco, L., Comia, H., Caravela, M., 2020. Capacity Building for Disaster Management in Mozambique Through Teaching Public Participatory GIS and Spatial Data Infrastructure. The International Archives of Photogrammetry, Remote Sensing and Spatial Information Sciences, 44, 151-158.

YouthMappers, 2021. YouthMappers. https://www. youthmappers.org/. [Online; accessed 14-June-2021]. 